\title{
Teaching and Learning and Self-Assessment in Nuclear Hospital (NH) versus Affiliated (AH) Hospitals Surgical Clerkship in the 6th year of the Faculty of Medicine - Oporto University (FMUP) (Analysis of 913 students)
}

\author{
João Paulo Araújo Teixeira ${ }^{1}$, Carlos Ribeiro ${ }^{1}$, Luís M. Moreira², José Amarante ${ }^{1}$
}

\section{Corresponding author:}

Professor Joăo Paulo Araújo Teixeira FMUP, Department of Surgery Alameda Prof. Hernâni Monteiro. 4200-319 Porto, Portugal E-mail: jpat@netcabo.pt

\begin{abstract}
'Department of Surgery, Faculty of Medicine University of Porto (FMUP), Portugal ${ }^{2}$ Research in Education and Community Intervention \& Health School of Vila Nova de Gaia - Piaget Institute, Vila Nova de Gaia, Portugal
\end{abstract}

\section{ABSTRACT}

Background: the increasing of the numerus clausus becomes difficult to perform surgical clerkship (6th year) in just one hospital. So it became necessary to have the collaboration of Affiliated Hospitals (AH). This research corresponds to the comparative analysis of that clerkship in those institutions.

Methods: A voluntary and anonymous assessment was conducted by 913 (49.3\%) of the 1851 students who attended surgical clerkship in the school years 2007-2008 to 2013-2014 in Oporto Medical School. Surveys were collected corresponding to the student's assessment of "teaching-learning" and "self-assessment", valued in a Likert scale from 1 to 5 ; surgical training and the perspectives for future specialization were equally assessed, before and after the clerkship. Results from the Nuclear Hospital (NH) vs AH were compared.

Results: In the comparative analysis of the $\mathrm{NH}$ vs $\mathrm{AH}$ there was a similar assessment of teaching-learning and self-assessment; however, concerning teaching-learning, several items received a higher rating in $\mathrm{AH}$ than in the $\mathrm{NH}$ : clinical training in outpatient center (3.80 vs $3.67 p=0.029$ ), emergency ( 4.02 vs $3.91 p=0.043$ ) and operating room ( 3.78 vs 3.62 $\mathrm{p}=0.024)$. Self-assessment in the $\mathrm{NH}$ was slightly worse than in the $\mathrm{AH}$, regarding the use of training opportunities (4.34 vs $4.41 \mathrm{p}=0.058$ ).

Conclusion: Assessment of the item "teaching and learning" proved to be superior in $\mathrm{AH}$ regarding clinical training in outpatient center, operating room and emergency. It must be considered that the collaboration of AH in the Surgical Clerkship of the 6th year students is a valid and effective alternative.

Abbreviations: NH - Nuclear Hospital (HSJ - Hospital de S. Joyo); AH - Affiliated Hospitals; FMUP - Faculty of Medicine, Oporto University

Key words: Medical education, Surgical Clerkship, Affiliated hospitals, Oporto Medical School

\section{BACKGROUND}

There has been, in recent years, a radical change in medical education 
essentially after Flexner report (1). The old rigid system, with almost exclusive appreciation for theoretical concepts was replaced by a system which appreciates practical aspects, placing students at the heart of problem solving related to the patient and based on the critical development of their cognitive attitudes $(2,3,4)$. It has been equally valued the interconnection between curricular units of basic sciences and clinical, encouraging research, and more recently transforming the last year of the course in a year directed to clinical practice.

These goals gain particular emphasis on the pedagogical methodology provided to students of the $6^{\text {th }}$ year, whose preparation constitutes the bridge between university and the future residency (5).

However, it is essential to evaluate the efficiency and the degree of satisfaction of those students at the end of the $6^{\text {th }}$ year.

Eyal (6) refers: "the necessity of gathering information from students and graduates to evaluate their medical education experience" and various publications reveal that not always the results are satisfactory. Thus, Chen (7) in a Harvard University research, in 2015, based on 2287 surveys conducted in 107 American universities, reports that only $53.8 \%$ of students considered themselves well prepared for the exercise of future residency. Similarly, Jaili (8) verified that $70 \%$ of students did not believe to be sufficiently trained in clinical skills for the future practice of medicine.

In this context, FMUP, whose organization of undergraduate education is well-defined in UP information platform (5) has sought to provide $6^{\text {th }}$ year students a vocational education, preparing them for future tasks of clinical life bringing them into contact with different specialties and hospitals $(9,10,11)$.
Regarding surgical clerkship, besides general surgery, partial clerkships in various surgical areas are provided by FMUP, according several medical schools, namely: general surgery, vascular, cardiothoracic, pediatric, plastic and reconstructive surgery, experiencing various sectors including the emergency department and the experimental surgery lab $(12,13,14,15,16)$.

However, giving the continuous numerus clausus increase it has become difficult, concerning general surgery, to successfully perform this clerkship in just one hospital (NH) and, for this reason, from 2005-2006 the collaboration of several $\mathrm{AH}$ was required, considering positive experiences regarding the extension of medical education to other hospitals in addition to the nuclear as well as following decisions taken by FMUP similarly to what happened in some universities (17).

It is, therefore, necessary to evaluate in detail, the efficiency of this methodology, comparing the results obtained in the $\mathrm{NH}$ (HSJ) with $\mathrm{AH}$, which is the aim of our research, through surveys answered by students, over eight successive years.

\section{METHODS}

The universe of this study consists of 1851 students (table 1). We collected a sample of 913 students (49.3\%) that voluntarily responded to an anonymous survey after attending to the surgical clerkship (6th year) at FMUP, in the school years from 2007-2008 to 2013-2014. There were 305 students were from the NH (Hospital São João) and 608 from AH (V. N. Gaia Hospital Centre - CHVNG, Hospital Padre Américo, Hospital Pedro Hispano - HPE, in Matosinhos, Central Hospital of Funchal and Hospital Divino Espírito Santo in Ponta Delgada) (table 2).

Table 1 - Distribution of students bynuclear hospital

\begin{tabular}{|c|c|c|}
\hline School Year & $\begin{array}{c}\text { Number of students enrolled } \\
\text { in the } 6 \text { th year }\end{array}$ & $\begin{array}{l}\text { Number of students who completed } \\
\text { the Integrated Master in Medicine }\end{array}$ \\
\hline 2007 & 183 & 183 \\
\hline 2008 & 198 & 198 \\
\hline 2009 & 242 & 236 \\
\hline 2010 & 239 & 227 \\
\hline 2011 & 260 & 242 \\
\hline 2012 & 275 & 261 \\
\hline 2013 & 242 & 230 \\
\hline 2014 & 288 & 274 \\
\hline Total & 1927 & 1851 \\
\hline$\%$ & $47.4 \%$ & $49.3 \%$ \\
\hline
\end{tabular}


Table 2 - Distribution of students by hospitals

\begin{tabular}{|c|c|c|c|c|c|c|c|c|c|c|c|}
\hline & & & \multicolumn{5}{|c|}{ Year } & \multirow[b]{2}{*}{2012} & \multirow[b]{2}{*}{2013} & \multirow[b]{2}{*}{2014} & \multirow[b]{2}{*}{ Total } \\
\hline & & & 2007 & 2008 & 2009 & 2010 & 2011 & & & & \\
\hline \multirow[t]{6}{*}{ Hospital } & $\mathrm{NH}$ & $\mathrm{N}$ & 38 & 26 & 26 & 30 & 43 & 51 & 51 & 40 & 305 \\
\hline & & $\%$ & $4.2 \%$ & $2.8 \%$ & $2.8 \%$ & $3.3 \%$ & $4.7 \%$ & $5.6 \%$ & $5.6 \%$ & $4.4 \%$ & $33.4 \%$ \\
\hline & $\mathrm{AH}$ & $\mathrm{N}$ & 67 & 47 & 63 & 63 & 85 & 100 & 117 & 66 & 608 \\
\hline & & $\%$ & $7.3 \%$ & $5.1 \%$ & $6.9 \%$ & $6.9 \%$ & $9.3 \%$ & $11.0 \%$ & $12.8 \%$ & $7.2 \%$ & $66.6 \%$ \\
\hline & Total & $\mathrm{N}$ & 105 & 73 & 89 & 93 & 128 & 151 & 168 & 106 & 913 \\
\hline & & $\%$ & $11.5 \%$ & $8.0 \%$ & $9.7 \%$ & $10.2 \%$ & $14.0 \%$ & $16.5 \%$ & $18.4 \%$ & $11.6 \%$ & $100.0 \%$ \\
\hline
\end{tabular}

At the beginning of the clerkship a Log Book is distributed to all students, equal in all hospitals, where all activities are recorded (some mandatory), and subsequently validated by tutors, through which frequency is assessed and attributed much of the clerkship evaluation.

This clerkship includes 4 weeks in general surgery in $\mathrm{NH}$ and $\mathrm{AH}$ and 1 week in each of the other surgical specialties only in $\mathrm{NH}$ (pediatric surgery, vascular, cardiothoracic, plastic and reconstructive). A short stay in the experimental surgery lab (FMUP) was included in the period of general surgery. Each student or group of 2 was mentored by one tutor (surgeon). The Director of Surgical clerkship was in permanent contact with hospitals, having organized regular meetings both with students, at the beginning and end of clerkship, and with those responsible for their medical education, in order to monitor training as well as final assessments.

At the end of each clerkship, all students voluntarily return an anonymous survey corresponding to the assessment of teaching-learning, self-assessment, general surgery training and future career prospects. In the group corresponding to teaching-learning, 14 items were considered with 5 possible answers, valued in a Likert scale (1-very poor, 2-poor, 3-fair, 4-good, 5-very good). Self-assessment group considers 5 possible answers (1-not at all, 2-slightly, 3-sufficient, 4-very, 5 -completly). The global surgical assessment was evaluated in (1-very poor, 2-poor, 3-good, 4-excellent). The results related to each item as well as the comparative analysis of the results obtained in the $\mathrm{NH}$ (HSJ) and in AH were globally evaluated. These surveys are distributed to all students simultaneously with the Logbook (10).

Statistical data analysis was performed using IBM SPSS Statistics, v.22. Observed and expected frequencies were compared using the Chi-square Test and the differences between groups were assessed using the Mann-Whitney Test. Reliability Analysis (Internal
Consistency Analysis and Factor Analysis) was performed to assess the instrument used in this study. Significative values were considered for $p<0.05$.

\section{RESULTS}

\section{Teaching and learning assessment (table 3)}

Items with average rating above "Good" are related to Overall impression (4.14), Support of teachers (4.10), Appropriate duration (4.09), Overall organization (4.05) and Consistency of the program objectives (4.03). Items related to learning style and Staff meetings have a lower average rating (3.54 and 3.49, respectively).

Teaching and learning assessment according to institutions (table 4)

Students from the $\mathrm{NH}$ and from $\mathrm{AH}$ made an

Table 3 - Teaching and learning assessment

\begin{tabular}{|c|c|c|c|}
\hline & $\mathbf{N}$ & Average & Standard Deviation \\
\hline Overall impression & 909 & 4.14 & 0.59 \\
\hline Support from teachers & 902 & 4.10 & 0.78 \\
\hline Appropriate duration & 907 & 4.09 & 0.85 \\
\hline Overall organization & 909 & 4.05 & 0.69 \\
\hline $\begin{array}{l}\text { Consistency of the program } \\
\text { objectives }\end{array}$ & 900 & 4.03 & 0.74 \\
\hline Clinical training (Emergency) & 910 & 3.98 & 0.93 \\
\hline Availability of other professionals & 899 & 3.88 & 0.81 \\
\hline Clinical training (Wards) & 910 & 3.83 & 0.87 \\
\hline Assessment methodology & 890 & 3.77 & 0.88 \\
\hline $\begin{array}{l}\text { Clinical training } \\
\text { (Outpatient Center) }\end{array}$ & 908 & 3.75 & 0.81 \\
\hline $\begin{array}{l}\text { Clinical training } \\
\text { (Operating Room) }\end{array}$ & 910 & 3.72 & 0.99 \\
\hline Other pedagogical activities & 847 & 3.72 & 0.89 \\
\hline Learning Style & 876 & 3.54 & 0.86 \\
\hline Staff meetings & 904 & 3.49 & 0.90 \\
\hline
\end{tabular}


Table 4 - Teaching and learning assessment according to institutions

\begin{tabular}{|c|c|c|c|c|c|c|c|}
\hline & NH & & & AH & & & \\
\hline & $\mathbf{N}$ & Average & Standard Deviation & $\mathbf{N}$ & Average & Standard Deviation & $\mathbf{p}$ \\
\hline Overall impression & 304 & 4,12 & 0,59 & 605 & 4,15 & 0,59 & 0,453 \\
\hline Global organization & 303 & 4,09 & 0,65 & 606 & 4,03 & 0,71 & 0,387 \\
\hline Support teachers & 302 & 4,15 & 0,77 & 600 & 4,08 & 0,78 & 0,230 \\
\hline Clinical training - Jobs & 304 & 3,85 & 0,82 & 606 & 3,82 & 0,90 & 0,790 \\
\hline Clinical training - Outpatient Center & 302 & 3,67 & 0,81 & 606 & 3,80 & 0,81 & 0,029 \\
\hline Clinical training - Emergency & 304 & 3,91 & 0,91 & 606 & 4,02 & 0,93 & 0,043 \\
\hline Clinical training - Operative room & 305 & 3,62 & 1,01 & 605 & 3,78 & 0,98 & 0,024 \\
\hline Other educational activities & 282 & 3,70 & 0,84 & 565 & 3,72 & 0,92 & 0,581 \\
\hline Staff meetings & 303 & 3,56 & 0,84 & 601 & 3,45 & 0,92 & 0,078 \\
\hline Learning styles & 297 & 3,63 & 0,78 & 579 & 3,50 & 0,89 & 0,079 \\
\hline Availability of other professionals & 300 & 3,84 & 0,75 & 599 & 3,89 & 0,84 & 0,210 \\
\hline Appropriateness to the objectives and program & 303 & 4,02 & 0,74 & 597 & 4,04 & 0,73 & 0,896 \\
\hline Duration of suitability & 304 & 4,09 & 0,83 & 603 & 4,10 & 0,86 & 0,701 \\
\hline Assessment methodology & 300 & 3,79 & 0,88 & 590 & 3,76 & 0,88 & 0,571 \\
\hline
\end{tabular}

identical average evaluation of teaching and learning on most items (probative values of over 0.05). However in the items related to Clinical training in the OR, Outpatient Center and Emergency department, the evaluation was lower in $\mathrm{NH}$ than in $\mathrm{AH}$ (probative values of $0.024,0.029$ and 0.043 , respectively).

\section{Self-Assessment}

Items related to Use of training opportunities and Involvement in care tasks are valued above "Very", with average values of 4.38 ( $\mathrm{sd}=0.63$ ) and 4.29 ( $\mathrm{sd}=0.68)$, respectively. The item related to Collaboration in pedagogical activities has an average value of 3.98 (sd=0.76), slightly below that level.

\section{Self-assessment according to institutions}

$\mathrm{NH}$ students assess themselves slightly worse than students from other institutions in the item related to Use of training opportunities (4.34 $\mathrm{sd}=0.62$ vs $4.41 \mathrm{sd}=0.63$ ), with a difference that, although not statistically significant, is on the border line $(p=0.058)$. In the other two items, selfassessment is identical.

\section{Comparison of teaching and learning and self-assessment areas}

Both self-assessment and the assessment of teaching and learning (in a scale of 0 to 1 ) is positive, with the first one having a higher average value (0.805 $s d=0.138)$ than the second $(0.718 s d=0.125)$.

\section{Comparison of teaching and learning and} self-assessment areas according to institutions

$\mathrm{NH}$ students and students from $\mathrm{AH}$ self-assess themselves (in a scale from 0 to 1 ) identically $(0.803$ $s d=0.131$ vs $0.806 s d=0.141)(p=0.492)$ and assessed, also identically, teaching and learning $(0.715 \mathrm{sd}=0.120 \mathrm{vs}$ $0.716 s d=0.128)(p=0.787)$. In both cases the selfassessment values are higher than the assessment of teaching and learning.

\section{Global surgical training}

Considering all of the students, $84 \%$ assessed their global surgical training as good or excellent. For $\mathrm{NH}$ students this percentage is $84.6 \%$, and in $\mathrm{AH}$ is $83.7 \%$.

\section{Future career perspectives}

Before clerkship, $57.8 \%$ of students had the perspective of performing a medical specialty, $41.0 \%$ a surgical specialty and $20.0 \%$ intended to be general practitioners.

In a global way, the perspectives in terms of career that students had prior to clerkship remained very similar to those after its completion. It is noteworthy, however, a $6.4 \%$ increase favouring the surgical specialty option, and a decrease of $2.7 \%$ in the general practitioners option and $2.3 \%$ in medical specialty. 


\section{Future career perspectives according to institutions}

In this item, there were no significant differences before and after clerkship in $\mathrm{NH}$ and $\mathrm{AH}$, except in the perspective of choosing a surgical specialty that increased slightly in the $\mathrm{NH}$ in relation to $\mathrm{AH}$.

\section{Reliability analysis}

\section{Internal consistency analysis: teaching and learning assessment (table 5)}

Internal consistency analysis resulted in a 0.866 Cronbach's alpha for the teaching and learning dimension, and a 0.708 alpha for the self-assessment dimension. This shows a good internal consistency of the instrument used in this study. In table 4 we present the corrected item-total correlations and alpha values considering the exclusion of each item.

\section{Factor analysis (table 6)}

We retained two main components in teaching and learning dimension that explain $46 \%$ of the accumulated variance. One is related to clinical teaching and the other related to assessment and curricular units' organization. On self-assessment dimension we retained three main components (corresponding to the three items in that dimension), which explains $100 \%$ of the accumulated variance. The following table shows the matrix components related to the teaching and learning dimension.

\section{DISCUSSION}

Assessing student's skills for medical performance
Table 5 - Internal Consistency Analysis: Teaching and Learning Assessment

\begin{tabular}{|c|c|c|}
\hline & $\begin{array}{l}\text { Corrected } \\
\text { Item-Total } \\
\text { correlations }\end{array}$ & $\begin{array}{l}\text { Alpha if } \\
\text { Item is } \\
\text { excluded }\end{array}$ \\
\hline \multicolumn{3}{|l|}{ Teaching and Learning Assessment } \\
\hline Overall impression & 0.655 & 0.853 \\
\hline Overall Organization & 0.579 & 0.855 \\
\hline Support from teachers & 0.582 & 0.854 \\
\hline Clinical training - Ward & 0.494 & 0.859 \\
\hline Clinical training - Outpatient Center & 0.468 & 0.860 \\
\hline Clinical training - Emergency & 0.456 & 0.861 \\
\hline Clinical training - Operating room & 0.430 & 0.863 \\
\hline Other pedagogical activities & 0.532 & 0.856 \\
\hline Staff meetings & 0.510 & 0.858 \\
\hline Didactic resource & 0.554 & 0.855 \\
\hline Availability of other professionals & 0.555 & 0.855 \\
\hline Adequacyto the objectives andprogram & n $\quad 0.682$ & 0.849 \\
\hline Appropriate duration & 0.440 & 0.861 \\
\hline Assessment methodology & 0.505 & 0.858 \\
\hline \multicolumn{3}{|l|}{ Self-assessment } \\
\hline Involvement in care tasks & 0.579 & 0.552 \\
\hline Collaboration in pedagogical activities & 0.496 & 0.667 \\
\hline Use oftraining opportunities & 0.515 & 0.635 \\
\hline
\end{tabular}

at the end of the course is one of the major current concerns of those responsible for medical education.

Ours results are a clear evidence of the good preparation offered by FMUP to students of the 6th year in surgical clerkship. Regarding global dimension, the item teaching-learning registered an evaluation of good -4in the following items: overall impression, support from teachers, appropriate duration, overall organization

Table 6 - Factor Analysis

\begin{tabular}{|c|c|c|c|}
\hline & \multicolumn{3}{|l|}{ Rotated Component Matrix } \\
\hline & & \multicolumn{2}{|c|}{ Component } \\
\hline & & $P<0.001$ & $P<0.001$ \\
\hline \multirow[t]{9}{*}{ Clinical teaching } & Clinical training - Operating room & 0.686 & \\
\hline & Clinical training - Emergency & 0.627 & 0.128 \\
\hline & Support from teachers & 0.605 & 0.336 \\
\hline & Other pedagogical activities & 0.596 & 0.256 \\
\hline & Clinical training - Outpatient center & 0.585 & 0.177 \\
\hline & Overall impression & 0.567 & 0.471 \\
\hline & Availability of other professionals & 0.508 & 0.388 \\
\hline & Clinical training - Ward & 0.436 & 0.375 \\
\hline & Staff meetings & 0.422 & 0.411 \\
\hline \multirow[t]{5}{*}{ Assessment and curricular units' organization } & Appropriate duration & $P<0.001$ & 0.752 \\
\hline & Assessment methodology & 0.138 & 0.714 \\
\hline & Adequacy to the objectives and program & 0.397 & 0.681 \\
\hline & Overall organization & 0.350 & 0.604 \\
\hline & Didactic resources & 0.326 & 0.577 \\
\hline
\end{tabular}


and consistency with the program objectives. The values obtained in the items staff meetings and didactic resources were the lowest, according to what was mentioned in an earlier publication (15).

In self-assessment, there were higher average levels regarding the use of training opportunities and involvement in care tasks than in collaborative pedagogical actions.

The values obtained in the evaluation performed according Cronbach's alpha showed a good internal consistency of the instruments used in this study.

In our research it is very important to note that comparative analysis of student assessment concerning general surgery in the $\mathrm{NH}$ vs $\mathrm{AH}$ revealed no significant difference in teaching-learning, though higher in $\mathrm{AH}$ with respect to training in the operating room, outpatient center and emergency; similarly, there were no differences in the students self-assessment who did their clerkship in both types of hospitals, although the $\mathrm{AH}$ revealed better use of training opportunities. Both institutions revealed higher averages in self-assessment than in teaching-learning. Global surgical training was, in general, good or very good, not registering significant differences between the $\mathrm{NH}$ and $\mathrm{AH}$, having both a similar result on this item. There are differences, although not significant, in choosing future medical careers, before and after clerkship.

The fact that the evaluation of the above items in the $\mathrm{AH}$ was not inferior to the $\mathrm{NH}$, being even superior in some of them, is noteworthy; this should be probably related to the lower patient-student ratio in affiliated hospitals in that only the latter be teaching exclusively students of the 6th year; besides the tutors, in these latter, are residents that have started the participation in the medical education recently and probably have a greater motivation to demonstrate the capabilities of their department and hospital. This allows the AH to have greater availability of tutors, allowing greater personalization in the contact between students and patients, particularly in wards, outpatient center, operating room and emergency.

Thus, in wards, students had the opportunity to participate in daily visits to patients and organizing medical records, being necessary, in these cases, consent from patients for collaboration in teaching (18, 19); however, in AH they had more opportunities to perform small acts such as urinary catheterization, nasogastric intubations, venipunctures, and administration of parenteral solutions, as well as make dressings to surgical wounds.

In the operating room, besides contacting with professionals from various areas (multidisciplinary team), they were confronted with the strict rules of behavior in this department. Students also had contact with aspects related to leadership of multidisciplinary teams, particularly in situations of stress, as sometimes occurs inside an operating room. There was an outspoken enthusiasm in relation to the various techniques of the several surgical specialties, particularly in general surgery and regarding minimally invasive surgery of which HSJ was one of the pioneers in Portugal (20). However, the lower differentiation of some patients resorting to the $\mathrm{AH}$, allowed a greater participation of students in the various surgical procedures, as aids, while under the guidance of their respective tutors.

The same happened in outpatient center, where there is the possibility to dialogue with patients in the pre and in the immediate postoperative care, besides contacting with a wide range of pathologies.

The stay through the emergency department was considered essential to the clinical experience of a surgical clerkship. Here, students contacted with critical situations of various kinds and in the convenient monitoring of emergencies.

They also had the opportunity to frequent the outpatient surgery area (21), analyzing indications and postoperative care inherent in the treatment of patients; however, it was more efficient in the $\mathrm{AH}$ than in the $\mathrm{NH}$ because of the vocation of the latter for more differentiated pathologies.

The experience in the experimental surgery lab, where they had the opportunity to perform minor surgical procedures and make sutures on models and small animals, is presented today with great relevance in medical education $(16,21,22,23)$; it was very helpful to all students, particularly those in the $\mathrm{AH}$, since they had greater opportunity to practice the abovementioned sutures in the "emergency department", in the treatment of small wounds; these cases are more frequent the $\mathrm{AH}$ than in the $\mathrm{NH}$, since the latter is oriented for more complex patients.

During clerkship, students were reminded of the importance of teaching-learning in problem solving (24), which is of particular interest, mainly in the performance of clinical tasks of the medical profession, as well as in the development of "learning styles" skills, internet, database consulting, literature and audiovisual methods, as well as inherent cognitive critical analysis $(25,26)$. The importance of this methodology justified its inclusion in the medical curriculum (27).

It is interesting to emphasize that despite the importance given in the survey to those "learning styles", the evaluation of this item is lower than in the others, though, slightly higher in the $\mathrm{NH}$. This is not a surprise 
given the best possibilities of audiovisual and bibliographic methods available in the $\mathrm{NH}$; in the future it is necessary to correct this gap.

Equally low was the assessment of staff meetings in $\mathrm{NH}$ and $\mathrm{AH}$, probably because students do not always feel encouraged to participate, since, in some cases, they serve to address hospital organization and department management. It would be important to provide a more active clinical manner to these meetings, presenting clinical oral cases and literature review (28).

With regard to future prospects in terms of career, there were not significant changes after Clerkship, against what might be expected, once the students are attending the last year of their undergraduate course and will have to choose specialty soon.

Several factors contributed for the good results, in particular the action of the tutors which has been properly valued in various publications. Thus, Roberts 29. refers that 19 "teaching fellowships" positions were created at Bristol University to collaborate in the students instruction at $7 \mathrm{AH}$, carefully specifying the goals to achieve (Top tips); the same was referred by Man 30), proposing to residents with tutors duties, frequency in the 4-week courses, where the various teaching methods are discussed. For the FMUP clerkship, surgeons with pedagogic experience in graduate studies were selected as tutors. Likewise we intend to praise the good technical and pedagogical level of the affiliated hospitals residents who participated as tutors.

Finally it is important to enhance the level of satisfaction reported by students who attended the 6th year clerkship Surgical essentially highlighting the important contribution provided by affiliated hospitals.

\section{CONCLUSION}

It is possible to conclude that the collaboration of the AH in Surgical Clerkship of FMUP students in the 6th year is a valid and efficient option, not being inferior to $\mathrm{NH}$. The indispensable need for a coordinator to lead the clerkship must be highlighted, ensuring good coordination of teaching in different hospitals, and the development of a well-built Logbook, in order to unify and standardize, as much as possible, both teaching and learning and the assessment of students, distributed across different hospitals.

\section{Competing interests}

The authors declare that they have no competing interests.

\section{Authors' contributions}

JPAT, CR and JA devised the study and drafted the manuscript. LM performed the statistical analysis.

\section{REFERENCES}

1. Cooke M, Irby DM, Sullivan W, Ludmerer KM. American medical education 100 years after the Flexner report. N Engl J Med. 2006 Sep 28;355(13):1339-44.

2. Finkel ML, Brown HA, Gerber LM, Supino PG. Teaching evidencebased medicine to medical students. Med Teach. 2003 Mar;25(2): 202-4.

3. Claridge JA, Fabian TC. History and development of evidence-based medicine. World J Surg. 2005 May;29(5):547-53.

4. Montori VM, Guyatt GH. Progress in evidence-based medicine. JAMA. 2008 Oct 15;300(15):1814-6. doi: 10.1001/jama.300.15.1814.

5. Guidelines for accrediatation and quality assurance of health care units for teaching in undergraduate medicine. University of Porto (Ed); 2003.

6. Eyal L, Cohen R. Preparation for clinical practice: a survey of medical students' and graduates' perceptions of the effectiveness of their medical school curriculum. Med Teach. 2006 Sep;28(6):e162-70.

7. Chen CA, Kotliar D, Drolet BC. Medical education in the United States: do residents feel prepared? Perspect Med Educ. 2015 Aug;4(4):1815. doi: 10.1007/s40037-015-0194-8.

8. Jalili M, Mirzazadeh A, Azarpira A. A survey of medical students' perceptions of the quality of their medical education upon graduation. Ann Acad Med Singapore. 2008 Dec;37(12):1012-8.

9. Snow N. The role of the specialist in undergraduate surgical education. Am J Surg. 1989 May;157(5):523-7.

10. Guialnformativo ECTS 2005/2006. FMUP, 2006

11. Estevăo-Costa J, Amarante JMT. Anexo à Caderneta de Estágio. 1 Apreciaçăo/reflexăo final do estágiopeloaluno. 2006, FMUP,

12. Mahalingam S, Kalia P, Nagendran A, Oakesshott P. Undergraduate exposure to plastic surgery: the medical student perspective. J Plast Reconstr Aesthet Surg. 2014 May;67(5):e125-6. doi: 10.1016/ j.bjps.2013.12.044. Epub 2014 Jan 8.

13. Snow N, Imbembo AL. Thoracic surgical content of an undergraduate surgical curriculum. Surgery. 1986 Jul;100(1):83-8.

14. Karp MP, Hassett JM, Doerr RJ, Booth FM, Petrelli N, Allen JE, et al. The role of pediatric surgery in the medical school curriculum. J Pediatr Surg. 1989 Jan;24(1):39-40; Discussion 41.

15. Estevăo-Costa J, Barbosa J, Amarante JM, Ferreira MA. A prática clínica de cirurgiana FMUP. Arq Port Cirurgia. 2007;16:65-75.

16. Araujo Teixeira JP, Amarante J. 0 serviço de cirurgia experimental da FMUP no ensinopré e pós-graduado da cirurgia. Arq. Port. Cirurgia. 2006; 15:57-60.

17. Imperato JC, Rand WM, Grable EE, Reines HD. The role of the community teaching hospital in surgical undergraduate education. Am J Surg. 2000 Feb;179(2):150-3.

18. Omid A, Daneshpajouhnejad P, Pirhaji O. Medical Students' and Physicians' Attitudes toward Patients' Consent to Participate in Clinical Training. J Adv Med Educ Prof. 2015 Jan;3(1):21-5.

19. Mühlhauser I, Albrecht M, Steckelberg A. Evidence-based health information and risk competence. Ger Med Sci. 2015 Jul 9;13:Doc11. doi: 10.3205/000215. eCollection 2015.

20. Teixeira JP, Ribeiro C, Pinto A, Goulart A, Maia JC, Pimenta A. Surgical management of acute cholecystitis (experience of 249 cases). Hepatogastroenterology. 2011 Mar-Apr;58(106):281-4.

21. Gutiérrez Romero JR, Bustos Molina F, García Moreno F. Criterios de selección de pacientes y Procedimientos. Capitulo nํ⒌ Cirugía Mayor Ambulatoria. Manual Práctico. Barcelona: Masson; 2002. p. 41-48.

22. da Costa PM, Santos J, Maio R, Santos A, Paredes F. The role of a basic surgical skills laboratory as viewed by medical students (6th year). Med Teach. 2001 Mar;23(2):176-180.

23. Dubrowski A, MacRae H. Randomised, controlled study investigating the optimal instructor: student ratios for teaching suturing skills. Med Educ. 2006 Jan;40(1):59-63. 
24. Mi M. Evidence based medicine teaching in undergraduate medical education: a literature review. Evidence based library and information practice. 2012;7(3):98-120.

25. Kim RH1, Gilbert T, Ristig K, Chu QD. Surgical resident learning styles: faculty and resident accuracy at identification of preferences and impact on ABSITE scores. J Surg Res. 2013 Sep;184(1):31-6. 2013 May 10.

26. Karimian Z, Kojuri J, Sagheb MM, Mahboudi A, Saber M, Amini M, et al. Comparison of residents' approaches to clinical decisions before and after the implementation of Evidence Based Medicine course. J Adv Med Educ Prof. 2014 0ct;2(4):170-5.

27. Shahidi F, Dowlatkhah HR, Avand A, Musavi SR, Mohammadi E. A study on the quality of study skills of newly-admitted students of Fasa University of Medical Sciences. J Adv Med Educ Prof. 2014 Jan;2(1): 45-50.

28. Chan MY. The oral case presentation: toward a performancebased rhetorical model for teaching and learning. Med Educ Online. 2015 Jul 17;20:28565. doi: 10.3402/meo.v20.28565. eCollection 2015.

29. Roberts D, Morris G, Crees A, Slade T, Jakeman N. Top tips for a teaching fellowship. Clin Teach. 2014 Dec;11(7):520-3. doi: 10.1111/ tct.12200.

30. Mann KV, Sutton E, Frank B. Twelve tips for preparing residents as teachers. Med Teach. 2007 May;29(4):301-6. 